\title{
Development of Monomethylol Urea for Coating Application: Effect of Time on Synthesis
}

\author{
Archibong $\mathrm{CS}^{1 *}$ and Osemeahon $\mathrm{SA}^{2}$ \\ ${ }^{1}$ Department of Chemical Sciences, Federal University, Nigeria \\ ${ }^{2}$ Department of Chemistry, Modibbo Adama University, Nigeria
}

Submission: January 04, 2019; Published: Febrauary 15, 2019

*Corresponding author: Christopher Sunday Archibong, Department of Chemical Sciences, Federal University Wukari, PMB 1020, Taraba State, Nigeria.

\begin{abstract}
Monomethylol Urea (MMU) was synthesis using the one step process, The MMU was characterized and evaluated at different Time interval. The viscosity, density, gel time, elongation at break, Refractive index, Turbidity as well as melting points were observed to either increase or decrease with increasing time interval with their optimal at $60 \mathrm{~min}$. while the formaldehyde emission and moisture uptake decreases with increasing time interval. Observations on solubility test shows that MMU resins were soluble from 0-60 min time interval beyond which it becomes insoluble, this is an indicator to the paint formulator that above this time interval, MMU cannot be used for paint formulation.
\end{abstract}

Keywords: Emulsion paint; Monomethylol urea; Binder; Time

Abbreviations: MMU: Monomethylol Urea; UF: Urea-Formaldehyde; FE: Formaldehyde Emission; OSP: One Step Process

\section{Introduction}

Polymers exhibit time-dependent, Optical, physical, mechanical and dielectric properties that can profoundly affect the functionality and durability of polymer products. Therefore, designing optimal materials for an application will need the thorough understanding of the effect of time. For example, inadequate knowledge of resin processing time could lead to slow degradation, color instability, poor durability, and loss of form. The knowledge of determining the best processing parameters is critical in any polymer product processing in order to obtain the desired end properties. To be able to tailor any of these properties controlling time-dependent behavior would be very advantageous.

Urea Formaldehyde UF resins are widely used in the coating and paint industry and they have become essential raw materials which are used in the wood and wood-based industry as adhesives for furniture and floors, tiles and the rest. Urea-formaldehyde (UF) resin, is one of the most important formaldehyde resins. In spite of its benefits such as fast curing, good performance in the panels, and lower cost; formaldehyde emission (FE) originated from either UF resin itself or composite products bonded by UF resins is considered a critical drawback as it affects human health particularly in indoor environment, UF hardness, brittleness, and poor water resistance also placed limitations on it usage and universal acceptability [1].
Recent research revealed that $30 \%$ of environmental VOCs originate from coating surfaces (Yudu.com, 2012). Coating material items in our environment is done for different purposes which include: protection, decoration, durability and for special purposes [2]. Latex paint is a water-based paint principally used for internal and external surface coatings, mostly in buildings for appearance and protection (Surajudeen and Zebulu, 2015). The essence of this present study is to assess a better understanding of the influence of the reaction time on the synthesis of monomethylol urea which was produced by modification of the UF resin, by decreasing the molar ratio of formaldehyde. This in turn will further decrease the present formaldehyde emission, hardness and brittleness associated with tetra, tri, and dimethylol urea.

\section{Materials and Methods}

\section{Resin synthesis}

MMU was prepared using the one step process (OSP) as reported by Osemeahon \& Archibong [2] with some modifications. One mole of urea $(6.0 \mathrm{~g})$ was made to react with one moles of formaldehyde $(8.11 \mathrm{ml}) 37-41 \%(\mathrm{w} / \mathrm{v})$, using $0.02 \mathrm{~g}$ of sodium dihydrogen phosphate as catalyst. The $\mathrm{pH}$ of the solution was adjusted to 7.30 by using $0.1 \mathrm{MH} 2 \mathrm{SO} 4$ and $0.5 \mathrm{MNaOH}$ solutions. The solution was heated in a thermostatically controlled water bath at $500 \mathrm{C}$. The reaction was allowed to proceed for $60 \mathrm{~min}$ 
after which the resin was removed and kept at room temperature (300C).

\section{Determination of gel time and viscosity}

The standard method of determining viscosity was employed using the viscometer bath and the u-tube viscometer with capillary inserted into the viscometer bath. A quantity of the sample of MMU resins was poured into the u-tube viscometer with capillary and then corked. The U-tube was suspended into the temperature of the viscometer bath containing water and the temperature was maintained constant. The cork was removed, and the time taken for the content to run-up starting from the top mark to the middle mark was noted using stopwatch. Gel time was measure by having a spindle rotate in the liquid until the time when rotation stops because the viscosity is too high, i.e. the material has gelled. Three different readings were taken for each sample and the average value calculated.

\section{Determination of moisture uptake}

The moisture uptake of the resin films was determined gravimetrically, according to method described by Osemeahon \& Dimas [3]. Known weights of the samples was introduced into desiccators containing a saturated solution of sodium chloride. The increase in weight (wet weight) of the sample was monitored until a constant weight was obtained. The difference between the wet weight and dry weight of the sample was recorded as the moisture uptake by the resin. Triplicate determinations were made for each sample and the average value recorded.

\section{Determination of elongation at break}

The elongation at break was determined using Inston Tensile Testing Machine (Model 1026). Resin films of dimension 50mm long, $10 \mathrm{~mm}$ wide and $0.15 \mathrm{~mm}$ thick was brought to rupture at a clamp rate of $20 \mathrm{~mm} / \mathrm{min}$ and a full load of $20 \mathrm{~kg}$. Three runs were carried for each sample and the average elongation evaluated and expressed as the percentage increase in length.

\section{Determination of density, turbidity, melting point and refractive index}

The density of the resins was determined by taking the weight of a known volume of resin inside a density bottle using Pioneer (Model PA64) weighing balance. Three readings were taken for each sample and average value calculated. The turbidity of the samples was determined by using Supertek digital turbidity meter (Model 033G). To determine the effect of melting point on Monomethylol urea (MMU), a melting point differential macrophase separation technique was developed. In this technique, MMU was introduced into a porcelain dish. The dish with it content was transferred into an oven set at $120 \mathrm{oC}$ for curing. The mixture was removed periodically from the oven and stirred until the mixture gelled and finally solidified. The temperature was then raised to $150 \mathrm{oC}$ and left for $5 \mathrm{~min}$ after which the sample was removed and cooled for observation. The experiment was repeated three times.

\section{Determination of formaldehyde emission}

Formaldehyde was carried out using the standard $2 \mathrm{~h}$ desiccator test as described by Osemeahon and Archibong [2]. The mold used was made from aluminium foil with a dimension of $69.9 \times 126.5 \mathrm{~mm}$ and thickness of $12.0 \mathrm{~mm}$. The emitted formaldehyde will be absorbed in $25.0 \mathrm{ml}$ of water and was analyzed by a refractometric technique using Abbe refractometer. Triplicate determinations were made for the samples and the average value taken.

\section{Determination of water solubility}

The solubility of MMU was determined by mixing $1 \mathrm{ml}$ of the resin with $5 \mathrm{ml}$ of distilled water at room temperature (300C).

\section{Effect of time on the viscosity of MMU}

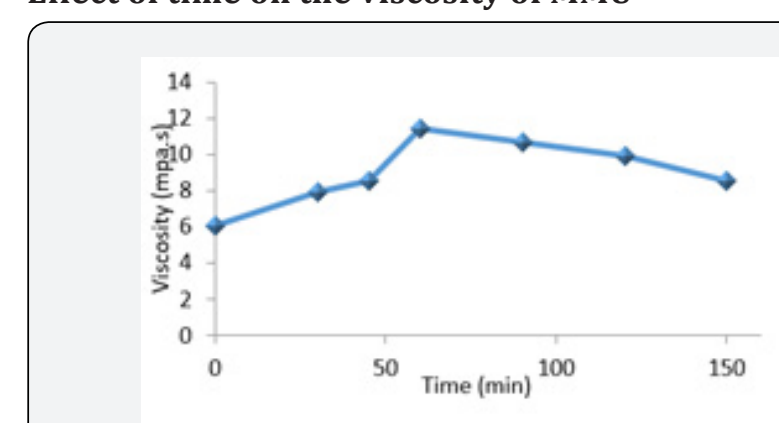

Figure 1: Effect of Time on the Viscosity of MMU.

Figure 1 is a graph of viscosity of MMU with changes in time. The viscosity is observed to rise with increasing time until it reaches a maximum at 60 minutes then it starts sloping. This effect is probably induced by the intrinsic shear-thinning properties of the MMU resin, whose viscosity is sensitive to shear rate, with a newtonian behavior at lower time interval, and then a pseudoplastic behavior at higher time induced by disentanglements phenomena (Julien et al., 2012). It could also be that as the time exceed $60 \mathrm{~min}$, the viscosity starts decreasing mainly because of the destruction of the bonds formed between urea and formaldehyde chains, and to the intrinsic pseudoplastic behavior of the monomethylol urea. The decrease in viscosity afterward results in a somewhat unstable viscosity at longer times, which is attributed to a shear-induced breaking of crosslink and/or polymer chains (Buitenhuis et al., 2003).

\section{Effect of time on the gel time of MMU}

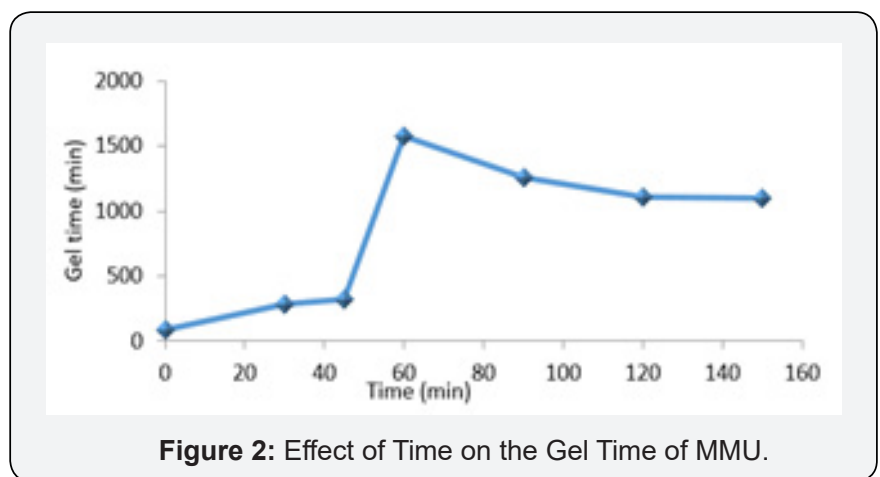


Figure 2, shows the graph of the effect of changes in time on the gel time of MMU resin. The gel time increases with increase in time until after 60 minutes, when it started descending, This behavior may be the result of the interaction of urea and formaldehyde enabling the formation of 3D network structures contributing to mechanical properties including covalent bonding, crystallization, and molecular secondary forces such as hydrogen bonding, molecular entanglements, and hydrophobic interactions as the time interval increases [4]. The decrease in gel-time with increasing time interval above $60 \mathrm{~min}$. may also be the result of molecular disentanglement, debonding and decrystallization because at gel point, a 3D network has not fully developed since there are many non- interacting segments such as dangling ends, stray chains, and loops existing within the MMU system (Weng et al.,2007). The gel point is the temperature or time at which the first set of covalent bonds connects across the sample (the onset of a three-dimensional network) and the molecular weight becomes infinitely large (Holly et al.,2004). Technically, gel-time enables a paint formulator to ascertain the optimum storage period of a binder before its utilization for paint formulation. It is also important in the determination of adhesion [5]. Urea is also very reactive compared to the larger chains, if greater amounts of free urea are available it will react with the chains more easily than two chains reacting with each other. The reaction with this free urea reaction will be opposed to the chain-chain reaction, which in turn will not cause a large increase in molecular weight [6].

\section{Effect of time on the melting point of MMU}

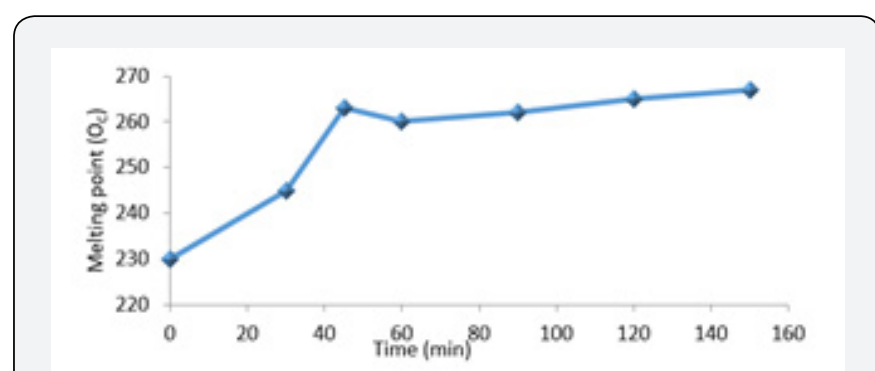

Figure 3: Effect of Time on the Melting point of MMU.

Figure 3 is a graph that shows the effect of time on the melting point of MMU resin. The melting point is observed to rise with increasing time up to an optimum at $60 \mathrm{~min}$. It has been demonstrated that crystallinity increases resulting to increasing melting point until above a critical time interval, the crystallinity decreases with increasing branch length, due to the inability of the longest chains to be incorporated in the crystalline structure [4]. More significantly, by increasing the number of short-branches with time, the polymer crystallinity and melting point can be reduced, since these side chains do not crystallize and are rejected into the amorphous regions of the polymer [7]. This induced non-linearity may also be attributed to polymer chain disentanglement with sufficiently large deformations and polymer chain debonding from the surface. It is also believed that this polymer as time interval elapses may contain atactic material, material that cannot crystallize, then it suggests that the melting point of the polymer containing less atactic material would be greater than those containing much of the atactic materials [8]. In the coating industry, the melting point of a binder is related to its thermal resistance as well as its brittleness. The thermal property, degree of cross linking, level of rigidity and molecular weight of the polymer is related to its melting point (Afsoon et al., 2011).

\section{Effect of time on the elongation at break of MMU}

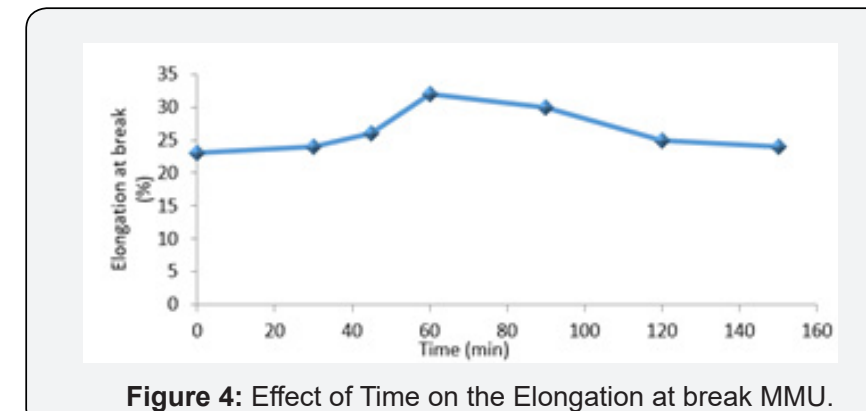

Figure 4 is a plot of the elongation at break of MMU against the changes in time. The elongation at break is initially observed to increase with increasing time but slightly started decreasing from 90 minute after attaining it zenith at $60 \mathrm{~min}$. In general, with plastics, an increase in molecular weight leads to improved rupture resistance, which is not necessarily reflected by an improvement in creep resistance and in fact may be associated with a decrease in creep resistance. An increase in molecular weight will also, in general, be associated with a decrease in processability, which will tend to give higher residual stresses in fabricated articles which can in turn influence rupture properties [9]. Therefore, it is obvious that the elongation at break was better between 50-60 minutes of time when molecular weight was not on the high side. This is referred to as 'under-curing' and resulted in a flexible product. When the time was increased to $90 \mathrm{~min}$ and above at a higher molecular weight build up, the elongation at break of the product was seen to decreased, as the degradation of the polymer was noticed at this stage. This is referred to as 'over-cured' and results in a partially weak product (Ram kumar et al., 2016). This slight reduction in tensile strength of the MMU composites with time at 90 min can also be attributed to relative decreasing of urea/formaldehyde matrix amount promoting adhesion force against shear fracture of polymer interface under load. The brittle character of these composites is dominated by the matrix fraction, the higher this fraction, the steeper is the composite de-loading (Velero et al., 2000). Finally, it is known that the failure of the composites can be attributed to weak bonding between MMU matrixes, presence of voids that leads to matrix fracture and pull-out.

Of the many properties of a plastic that influence its choice for a particular article or application, the ability to resist the inevitable sharp blows and drops met in day-today use is one of the most important. Elongation at break is a significant factor 
recounting the rupture performance of composites. It is the ratio between increased length and initial length after breakage of a tested material (Wu, et al., 2000).

\section{Effect of time on the formaldehyde emission of MMU}

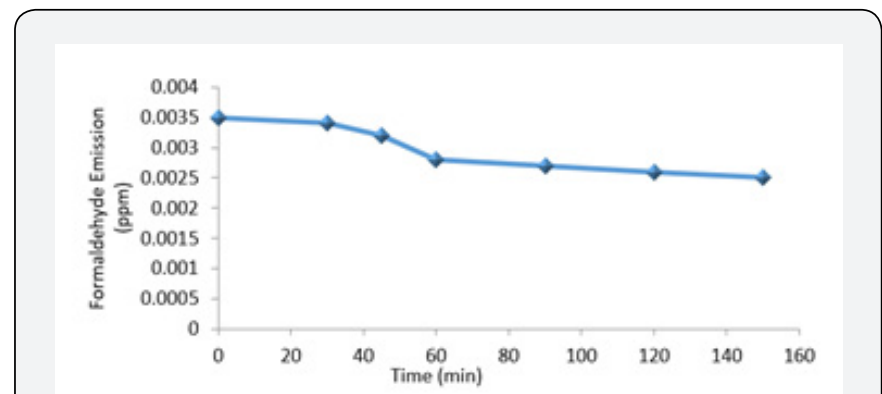

Figure 5: Effect of Time on the Formaldehyde Emission of MMU.

The plot of formaldehyde emission of MMU against the changes in time is shown in Figure 5. Formaldehyde emission is seen to reduce steadily with increasing time interval. This divergence could be due to the resin synthesis process, taking into account the fact that the samples were all prepared in the same Urea/Formaldehyde (U/F) 1:1 molar ratio and in an alkaline environment. In addition, alkaline environment behaves as an obstacle disrupting the MMU matrix and therefore, making it more difficult for the reactive group of urea and formaldehyde to come close and interact [10,11]. Also, George (2004) reported that the degree of resin polymerization does not affect the free formaldehyde content between $\mathrm{F} / \mathrm{U}$ and that free formaldehyde content is only moderately change by reaction concentration, or reaction time and temperature between $\mathrm{F} / \mathrm{U}$. The gradual reduction in formaldehyde emission may also be as a result of reduction in stress during cure which reduces emission resulting from improved flexibility, the presence of smaller molecules, like water and urea, after a long time can diffuse between larger chains and thus keep them from interacting with each other [4]. Formaldehyde emission in the curing process is one of the major disadvantages of urea formaldehyde resin which has led to restrictions on its use by regulatory organizations (Witold et al, 2008). Therefore, it is very important to determine the formaldehyde emission from synthesized urea-formaldehyde resin prior to its application [12].

\section{Effect of time on the moisture uptake of MMU}

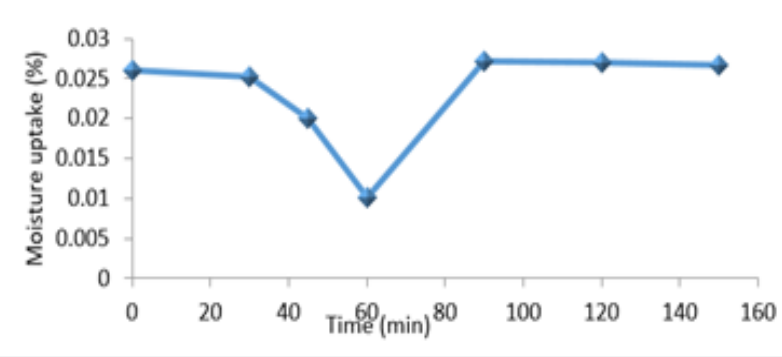

Figure 6: Effect of Time on the Moisture Uptake of MMU.
Figure 6 shows the moisture uptake of MMU with changes in time. MMU was observed to decrease with increase in time until at 90 min when it absorbed its highest moisture uptake. The porosity of the composite, the diffusion of water molecules between polymer chains and the capillary transport at the interfaces with increase in time could be the reason for the sudden upshot in moisture uptake of the MMU resin. Also, the extent of moisture absorption is closely related to crystallinity, by increasing the number of short-branches with time, the polymer crystallinity is reduced, since these short and side chains do not crystallize, water absorption becomes eminent. Also, the molecular size holes in the polymer structure may be expanding with increasing time interval, since transport of water in a polymer network is related to the availability of these molecular-sized holes [13].

Moisture uptake in polymeric materials is very important on both physical and structural levels. In synthetic resins used as binders, it is responsible for blistering, alligatoring, brooming etc, of paint film, affecting its mechanical properties in a way that might lead to the paint's failure [14].

\section{Effect of time on the refractive index of MMU}

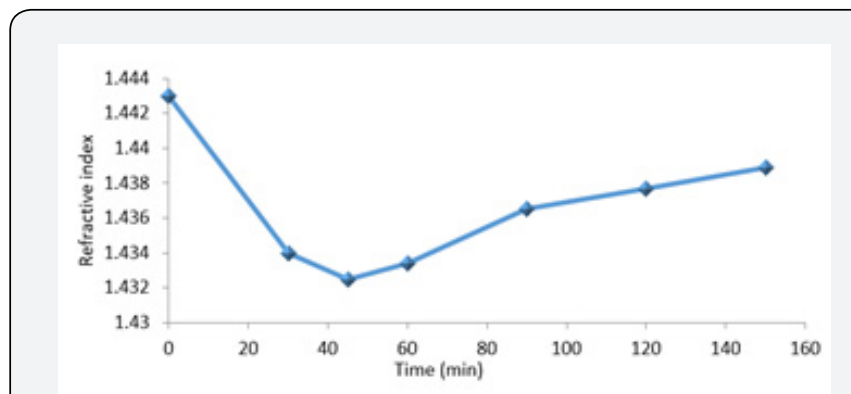

Figure 7: Effect of Time on the Refractive index of MMU.

Figure 7, is a plot of graph of time against the refractive index of MMU. The refractive index is observed to initially decrease gradually with increasing time until at $60 \mathrm{~min}$, where it started rising. The decrease in refractive index could be attributed to the microphase separation between urea and formaldehyde with increasing time [13]. The alteration of the crystallinity of the system with time give rise to higher crystallinity which in turn causes increase in molecular weight and hence the differences in the interaction with light [15]. The slight increase at $60 \mathrm{~min}$. interval may also probably be due to sedimentation of larger particles with increasing time (Julien et al., 2012). The gradual rise in the refractive index with increasing time, may also be due to the increasing discontinuities in the molecular structure of the blend, and the differences in the level of specific interaction in the resin mixture thereby creating light scattering $[16,17]$.

The refractive index as a specular component is a surface phenomenon, which is expressed as a function of the incidence angle and refractive index of the material, the surface roughness and a geometrical shadowing function. Gloss is a necessary coating property when the purpose is for surface aesthetic or 
decoration. Low gloss coating has been traditionally formulated by raising pigment concentration to a point where the roughness induced by the protruding pigment particles causes most of the incident light to be scattered in all direction (Osemeahon and Barminas, 2007).

\section{Effect of time on the density of MMU}

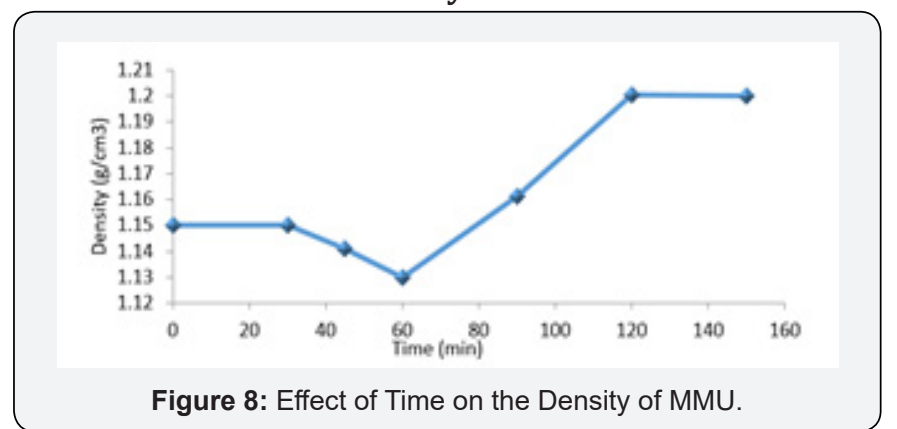

Figure 8 shows the graph of density of MMU with changes in time. The density of MMU decreases gradually from 1-60min then rise again. This may be as a result of rearrangement of molecular chains during chain folding. "This reeling in" of chains during crystallization leads to disentanglement of the chain from the solution more pronounce, resulting in a lower entanglement density [6]. The effects of saturated time are complex, higher saturation time not only enhances the free volume of polymer and the mass transfer, it also result in decrease in densities (Yajun and Sanjiu, 2015). It appears that during later stages of polymerization process the morphology of MMU undergoes some transformation accompanied by the formation of smaller pores and probably the densification of the polymer richdomains. That is, the non-crystalline regions together with the atactic segments are now considered as trapped within the large 'crystallites' themselves producing an increase in density with no similar increase in crystallinity [7]. The density of a paint binder has great influence on properties such as, brushability of the pait, pigment dispersion, flow, levelling and sagging [3].

Table 1: Effect of Time on the Water solubility of MMU.

\begin{tabular}{|c|c|}
\hline Time (min) & Solubility \\
\hline 0 & Soluble \\
\hline 30 & Soluble \\
\hline 45 & Soluble \\
\hline 60 & Soluble \\
\hline 90 & Insoluble \\
\hline 120 & Insoluble \\
\hline 150 & Insoluble \\
\hline
\end{tabular}

Table 1 presents the effect of Time on the solubility of MMU composite. It is observed that the resin is soluble in water up to a time interval of $60 \mathrm{~min}$ after which the resin form dispersions in water. When the time interval became longer it leads to the formation of globule-like conformation that most often lead to insolubility in pure water [18]. Also, the effect of interchain repulsions due to increasing time interval allows hydrophobes to take part at least to some extent in intramolecular associations.
This increasing hydrophobic behavior is expected as the time interval increases [19-25]. In the development of amino resins for emulsion paint formulation, resin solubility or dispersability in water is an important factor in the resin's acceptability [2532].

\section{Conclusion}

In this paper, the effect of processing time on the synthesis of Monomethylol urea was investigated, alongside some physical properties that can be exploited for paint formulation. The formaldehyde emission, moisture uptake and elongation at break were within the acceptable limit in the coating industry in terms of environmental safety, water resistance and flexibility respectively. This study allows manufacture of paint with low formaldehyde emission, as well as introducing flexibility and water resistance to paint by designing optimal time for processing of the MMU for applications as a binder.

\section{References}

1. Osemeahon SA, Archibong CA (2011) Development of urea formaldehyde and polyethylene waste as a copolymer binder for emulsion paint formulation. J Toxicol Environ Health Sci 3(4): 101-108.

2. Osemeahon SA, Dimas BJ (2014) Development of urea formaldehyde and polystyrene waste as copolymer binder for emulsion paint formulation. Journal of Toxicology and Environmental Health Sciences 6(3): 75-88.

3. Ming Cao, Taohong Li, Jiankun Liang, Guanben DU (2017) The influence of $\mathrm{pH}$ on Melanine-Dimthylurea-Formaldehyde Co-condensations: A Quantitative 13C-NMR Study. Polymer 10(9): 1-12

4. Menkiti MC, Onukwuli OD (2011) Utilization potentials of rubber seed oil for the production of alkyd resin using variable base oil lengths. New York Sci J 4(2): 51-59.

5. Bin Feng, Xiang Fang, Huai-Xi Wang, Wen Dong, Yu-Chun Li (2016) The Effect of Crystallinity on the Conpressive Properties of AL-PTFE. J of Polymers 8(10): 356-362.

6. Stefena Acierno, Peter Van Puyvelde (2005) Effect of short chain branching upon crystallization of model polyamides-11. J polymer 46(23): 10331-10338.

7. Rey F, Ferreira MA, Facal P, Machado AS (2018) Effect of Concentration, $\mathrm{pH}$, and Ionic Strength on the Viscosity of solutions of Soil Fulvic acid. Can J Chem 7(4): 295-299.

8. Rinat Nigmatillin, Martin Benesik, Fengge Gao (2014) Influence of Polymerization Conditions on the Properties of Polymer/Clay Nanocomposite Hydrogel. J Royal Society of Chemistry 10: 2035-2046.

9. Lee J Jeon, Kim S (2011) Green adhesives using tannin and Cashew nut shell liquid for environmental-friendly furniture materials. J Korean Furniture society 22(3): 219-229.

10. Abdullah ZA, Park BD (2010) Influence of Acrylamide Copolymerization of Urea-Foemaldehyde resin adhesives to their Chemical Structure and Performance. Journal of Applied polymer Science 117(6): 31813186.

11. Hamad K, Kaseem M, Deri F (2010) Effect of recycling on rheological and mechanical properties of poly (lactic acid)/ polystyrene polymer blend. Journal of Materials Science 46(9): 3013-3019.

12. Archibong CS, Osemeahon SA, Ushie OA, Ugwuja DI (2018) Trimethyol Urea and Polyethylene waste composite as Binder for Emulsion Paint Formulation. Int J Moderm Chem 10(1): 1-13. 
13. Akinterinwa A, Osemeahon SA, Nkafamiya II, Dass PM (2015) Formulation of Emulsion Paint from a Copolymer Composite of Dimethyol Urea/Polystyrene. J Chemistry and Materials Research 7(7): 20-25.

14. Jain W (2008) Evaluation of second generation indirect composite resins. A thesis submitted to the faculty of the University Graduate School in partial fulfilment of the requirements for the degree, Master of Science in the Department of Dental Materials, Indian University, Idianapolis, pp. 1-94.

15. Qi GR, Wang YH, Li XX, Peng HY, Yang SL (2002) Viscometric study on the specific interaction between proton-donating polymers and proton-accepting polymers. J Appl Polym Sci 85(2): 415-421.

16. Liem H, Etchegoin P, Whitehead KS, Bradley DDC (2002) Raman Scattering as a probe of morphology in conjugated polymer thin films. Journal of Applied Physics 92(2): 1154-1161.

17. Yunusa Umar BF, Abu-Sharkh SK, Asrof Ali (2005) The Effect of Zwitterion and Anionic Charge Densities in polymer Chains on the viscosity Behaviour of a pH-Responsive Hydrophobically Modified Ionic Polymer. J App Polymer Sc 98(3): 1404-1411.

18. Fatma Meydeneri Tezel, Ishak Atsin Karper (2017) Effect of pH on Optical and Structural Characterization of Chemical Deposit AgI thin films. Mat Res J 20(6): 8-25.

19. Cakic MS, Ivana SR, Vladislav MJ, Radmilaz R, Olivera ZI, et al. (2012) Investigation of the curing kinetics of alkyd-melamine-epoxy resin system. Progress in organic coatings 73 (4): 415-424.

20. Cakir M, Kartal I, Demirer H, Samur R (2012) Effect of water absorption on the wear behavior of sol-gel processed epoxy/silica hybrids. Scientific research and essays 7(7): 805-812.

21. Elham Katonizadeh, Kamal Janghortam (2018) Investigating the effect of synthesis condition on the Formation of Urea-Formaldehyde Microcapaules. Journal of Material Research and Technology 6(5): 250-262.
22. Ferrándiz Mas V, García Alcocel E (2013) Durability of expanded polystyrene mortars. Construction and Building Materials 46: 75-182.

23. Hwang Y, Sangmook L, Youngjae Y, Kwangho J, Lee W (2012) Reactive extrusion of polypropylene/polystyrene blends with supercritical carbon dioxide. Macromolecular Research 20(6): 559-567.

24. Kaniappan K, Latha S (2011) certain investigations on the formulation and Characterization of polystyrene/poly(methyl methacrylate) Blends. International Journal of ChemTech Research 3(2): 708-717.

25. Kazys R, Rekuviene R (2011) Viscosity and density measurement methods for polymer melts. Ultragarsas "Ultrasound" 66(4): 20-25.

26. Kim MG, Kanatzidis MG, Facchetti A, Marks TJ (2011) Low-Temperature Fabrication of high-Performance Metal Oxide Thin-Film electronics via combustion Processing. Nat Mater 10(5): 382-388.

27. Joakin Jeremeseff (2012) Investigation of UF-resins - the Effect of the Formaldehyde/Urea Molar Ratio during Synthesis. pp. 108.

28. Alavi Nikje MM, Abedinifar F, Idris A (2011) Epoxidized Soybean Oil Ring Opening Reaction under MW Irradiation, 3(3): 383-388.

29. Stephanie Pappa (2011) Oldest human paint making studio discovered in cave. Live Science 2011.

30. Akpabio UD (2012) Effect of $\mathrm{pH}$ on the properties of Urea Formaldehyde Adhesives. Int J of Modern Chem 2(1): 15-19.

31. Udeozo IP, Eboatu AN, UgwuOkechukwu PC, Chukwuemeka IM, Eze-Stephen PE (2013) Preparation and Characterization of Poly (Methyl methacrylate) (PMMA) and poly (Vinyl Chloride) (PVC) alloy. The Expt Int J of Sc and Tech 13(4): 859-863.

32. Yi Xu, Linhua Jiang, Jinxia Xu, Yang Li (2012) Mechanical properties of expanded polystyrene lightweight aggregate concrete and brick. Construction and Building Materials 27(1): 32-38.

\section{Your next submission with Juniper Publishers will reach you the below assets}

- Quality Editorial service

- Swift Peer Review

- Reprints availability

- E-prints Service

- Manuscript Podcast for convenient understanding

- Global attainment for your research

- Manuscript accessibility in different formats

( Pdf, E-pub, Full Text, Audio)

- Unceasing customer service

Track the below URL for one-step submission

https://juniperpublishers.com/online-submission.php 